Review Article

iMedPub Journals

www.imedpub.com

\section{Evolution of the Complications of Pedicular Arthrodesis over the Last Two Decades: A Meta-Analysis}

\section{Abstract}

In the last two decades, pedicular arthrodesis has become a popular surgical practice, supported by a growing technology of the products available in the market. In spite of its generalized use aiming at the improvement in the stabilization of the vertebral column and based on the anatomical location of neural structures, with proximity to the vertebrae and in the complex biomechanics of the spine, several kinds of complications were described, some doubts aroused about its safety and effectiveness.

Keywords: Spinal Instrumentation; Complications; Pedicular arthrodesis

Received: December 06, 2017; Accepted: December 26, 2017; Published: December 30, 2017

\section{Introduction}

Pedicle screw instrumentation allows better correction of spinal deformities in the thoracic and lumbar regions, such as idiopathic scoliosis, congenital kyphoscoliosis, kyphosis since its introduction by Roy-Camille in the 1980s [1]. The literature mentions the possibilities of better anchoring force compared to other available fastening techniques [2].

Currently, the most widely used screw insertion techniques are: freehand, fluoroscopic guides, CT based navigation. The free hand technique refers to the technique that uses bone markers for screw insertion without the assistance of any intraoperative image [3]. The most used currently is the one that is performed with intraoperative radiological aid. Computed tomography navigation refers to optoelectronic browsers with the use of computerized tomography to create a three-dimensional image of the spine [4].

\section{Objective}

The objective of the present review is to explain the main causes of complications in an attempt to avoid such situations as much as possible, as well as to evaluate the possibilities of a decrease in the prevalence of complications secondary to pedicle screws over the last 20 years.

\section{Methods}

We considered mainly the meta-analyzes in the English literature, and some prospective clinical studies with a number no inferior

\section{Nonato $\mathrm{MB}^{1 *}$, Prandini $\mathrm{MN}^{2}$} and Balestrieri JVL ${ }^{3}$

\author{
1 Department of Medicine, University of \\ Adamantina-Uni FAL, Brazil \\ 2 Department of Neurosurgery, Federal \\ University of Sao Paulo, Brazil \\ 3 Department of Medicine, University of \\ Grandes Lagos-UNILAGO, Brazil
}

\section{*Corresponding author: Nonato MB \\ झmbn01@hotmail.com}

Department of Medicine, University of Adamantina-Uni FAL, Elipidio Nunes da Cunha, 105, Caranda Bosque 1, Campo Grande, Mato Grosso do Sul, Brazil.

Tel: +55067998711224

Citation: Nonato MB, Prandini MN, Balestrieri JVL (2017) Evolution of the Complications of Pedicular Arthrodesis over the Last Two Decades: A Meta-Analysis. Spine Res. Vol.3 No.3:20

to 100 patients. We selected articles reporting the results of complications secondary to spinal instrumentation, both thoracic and lumbar. The MEDLINE, PUBMed databases were used for the literature search that covered the period from January 2001 to November 2017.

\section{Literature Review}

Chronologically, an analysis was made on the percentages of complications related to poor positioning.

In a study carried out in South Korea with 432 patients submitted to fixation of 4604 thoracic pedicle screws followed prospectively for more than 2 years, poor screw positioning was detected in 67 screws of 48 patients $(10.4 \%)$, referring to the main complication of the procedure. The neurological complications were related to the screws in 4 patients $(0.8 \%)$, specified in a transient paraparesis and 3 dural injuries. It was also reported, in mechanical complications, 11 intraoperative fractures of the pedicle, 35 loosening of screws and framed in vascular complications, 9 postoperative infections [5]. 
An extensive review analyzed the position of 37,337 total pedicular screws implanted evaluating the presence or not of the positioning violation, concluding that the placement precision was higher in patients with assisted navigation in vivo, with $95.5 \%$ accuracy compared when navigation was not used. However, they also reported that in thoracic surgeries, both in vivo and cadaveric populations, there was no advantage with the use of navigation [6].

Silvestre et al. submitted 115 patients to 1035 transpedicular thoracic screws, obtaining the results: 15 patients with intraoperative pedicle fracture (13\%); 14 patients with dural tear (12.1\%); 13 patients with poor screw positioning (10.4\%) and 2 patients with superficial wound infections (1.7\%).

The perioperative complications in 183 patients submitted to instrumentation, analyzed and considered low by Deng et al. were into $8.4 \%$ and subdivided: $3.8 \%$ of infection, $1.5 \%$ of pedicle fracture, $1.6 \%$ of pneumothorax and pleural effusion. In the segment, the main complication was loss of correction of deformity, $1.6 \%$ of the total complications in the follow-up [7].

A bibliographic review of 23 studies compared the effectiveness of instrumentation guided by navigation techniques (719 patients with 3555 screws) with the ones that were not assisted (569 patients and 2437 screws). There were no neurological complications related to instrumentation in the navigation group, but in the non-guided group there were 13 cases of neurological complications $[8,9]$. The authors concluded that the complications are rare but severe when happening. They can be avoided by careful planning of the surgery as well using of guided imaging navigation techniques which can assist the surgeon in preventing complication by providing accurate anatomical guidance for the procedure [10].
In a study in USA with a homogeneous population of 208 adolescents with idiopathic scoliosis and a mean age of 14.9 years, a total of 1.123 thoracic pedicular screws were inserted (5,4 thoracic screws/patient). In the defined complications as directly related to the screws, the poor positioning of the screws was mentioned, since the postoperative CT was performed in only 19 of the 208 patients (9.1\%). The radiographic evaluation showed possibility of aberrant trajectory in 23 screws, of 219 bolts evaluated. The dural tear was observed in 3 patients (1.4\%) evidenced by leakage of cerebrospinal fluid when the screw holes were prepared. Intraoperative pedicular fractures were reported in 2 patients $(0.9 \%)$ being attributed to attempts to the screw introduction. Three cases demonstrated radiographic evidence of the loosening of the screws due to poor positioning, with no clinical signs presented by the patient. One factor that should be mentioned is that in this study the studied population was of Chinese nationality, since the literature mentions some evidence that the pedicle morphology is unique in Chinese patients.

A meta-analysis that evaluated 21 studies with a total population of 1666 patients and 4570 pedicular screws by adolescent scoliosis (mean of 17.6 years of age), revealed a poor positioning of $15.7 \%$ of the thoracic screws, diagnosed by means of post-operative CT imaging. Other complications have also been reported, but no quantification of dural tear, infection, pseudarthrosis and transient neurological damage were reported. There were no major vascular complications.

Gelalis et al. in a meta-analysis, evaluated 26 prospective clinical studies with a total of 1.105 patients, in which 6,617 screws were inserted. They concluded that navigation exhibits better precision when compared to the free-hand technique and fluoroscopy. Specifically, CT navigation seems to be more accurate when compared to the other techniques evaluated.

Table 1 Comparison of positioning of screws.

\begin{tabular}{|c|c|c|c|c|}
\hline Year & Authors & $\begin{array}{l}\text { Number of } \\
\text { patients }\end{array}$ & Number of screws & Results \\
\hline 2001 & $\begin{array}{c}\text { Suk SE-II, Kim WJ, Lee SM, Kim JH, Chung } \\
\text { ER }\end{array}$ & 432 & $\begin{array}{l}4604 \text { thoracic pedicle } \\
\text { screws }\end{array}$ & $\begin{array}{l}\text { Poor screw positioning in } 67 \text { screws of } 48 \text { patients } \\
\qquad(10.4 \%)\end{array}$ \\
\hline 2007 & Kosmopoulos V, Schizas C & - & 37,337 & $\begin{array}{l}\text { The placement precision was higher in patients with } \\
\text { assisted navigation in } \\
\text { vivo. }(95,5 \%)\end{array}$ \\
\hline 2007 & Di Silvestre et al. & 115 & $\begin{array}{l}1035 \text { transpedicular } \\
\text { thoracic screws }\end{array}$ & $\begin{array}{l}15 \text { patients with intraoperative pedicle fracture }(13 \%) \text {; } \\
14 \text { patients with dural tear }(12.1 \%) ; 13 \text { patients with poor } \\
\text { screw positioning }(10.4 \%)\end{array}$ \\
\hline 2009 & $\begin{array}{c}\text { Deng Y, Zhou Y, Lu G, Wang B, Li J, Kang } \\
\text { Y, Lu C, Liu W, Ma Z }\end{array}$ & 183 & - & $\begin{array}{l}\text { The main complication was loss of correction of } \\
\text { deformity, } 1.6 \% \text { of the total complications }\end{array}$ \\
\hline 2010 & $\begin{array}{c}\text { Verma R, Krishan S, Haendlmayer K, } \\
\text { Mohsen A }\end{array}$ & 569 & 2437 & $\begin{array}{l}\text { In the non-guided group there were } 13 \text { cases of } \\
\text { neurological complications. }\end{array}$ \\
\hline 2010 & $\begin{array}{l}\text { Li G, Lv G, Passias P, Kozanek M, Metkar } \\
\text { US, Liu Z, Wood KB, Rehak L, Deng Y }\end{array}$ & 208 & $\begin{array}{l}1.123 \text { thoracic } \\
\text { pedicular screws }\end{array}$ & Poor positioning in 19 of the 208 patients (9.1\%) \\
\hline 2010 & Hicks JM, Singla A, Shen FH, Arlet V & 1666 & 4570 & Poor positioning of $15.7 \%$ of the thoracic screws. \\
\hline 2012 & $\begin{array}{c}\text { Gelalis ID, Paschos NK, Pakos EE, Politis } \\
\text { AN, Arnaoutoglou CM, Karageorgos AC, } \\
\text { Ploumis A, Xenakis TA }\end{array}$ & 1105 & 6617 & $\begin{array}{l}\text { Navigation exhibits better precision when compared to } \\
\text { the free-hand technique and fluoroscopy. }\end{array}$ \\
\hline 2014 & $\begin{array}{c}\text { Dede O, Ward WT, Bosch P, Bowles AJ, } \\
\text { Roach JW }\end{array}$ & 480 & 5923 & $\begin{array}{l}\text { Poor positioning in } 6 \text { patients, totaling only } 8 \text { screws } \\
\qquad(0.14 \%) .\end{array}$ \\
\hline
\end{tabular}


Another very low frequency of complications was reported in a retrospective study carried out in Pittsburgh over 12 years with 480 patients and 5923 screws inserted. With TC only in the 9 patients $(1.9 \%)$ symptomatic, there was a poor positioning in 6 patients, totaling only 8 screws $(0.14 \%)$. Of the remaining 3,2 had root compression and only 1 had orthostatic headache due to leakage of cerebrospinal fluid.

\section{Results}

With regard to 20 articles, only 9 could be selected for analysis. Comparatively, during the period of 2001-2009 a percentage of $22.7 \%$ of complications were reported, and in the period between 2010-2014 there was a drop to $12.4 \%$ of complications.

In both decades, the most mentioned complication refers to poor positioning of the screws. Considering the period evaluated, a $10.3 \%$ decrease in complications secondary to spinal instrumentation could be observed (Table 1).

\section{Discussion}

Besides considering the publications that were analyzed and compared, we obtained two articles that concluded that the intraoperative navigation significantly reduced the poor screw positioning, so it is important to point out that the techniques of navigation by CT and other orientation technologies are important factors for better operations.

\section{References}

1 Dede O, Ward WT, Bosch P, Bowles AJ, Roach JW (2014) Using the freehand pedicle screw placement technique in adolescent idiopathic scoliosis surgery: What is the incidence of neurological symptoms secondary to misplaced screws? Spine (Phila Pa 1976) 39: 286-290.

2 Deng Y, Zhou Y, Lu G, Wang B, Li J, et al. (2009) Complication of thoracic pedicle screw fixation in spinal deformities. Zhong Nan Da Xue Xue Bao Yi Xue Ban 34: 820-824.

3 Di Silvestre M, Parisini P, Lolli F, Bakaloudis G (2007) Complications of thoracic pedicle screws in scoliosis treatment. Spine (Phila Pa 1976) 32: 1655-1661.

4 Gelalis ID, Paschos NK, Pakos EE, Politis AN, Arnaoutoglou CM, et al. (2012) Accuracy of pedicle screw placement: A systematic review of prospective in vivo studies comparing free hand, fluoroscopy guidance and navigation technigues. Eur Spine J 21: 247-255.

5 Hicks JM, Singla A, Shen FH, Arlet V (2010) Complications of pedicle screw fixation in scoliosis surgery: A systematic review. Eur Spine J 35: 465-470.
With the reduction of $10.3 \%$ of the complications in the period evaluated, it is clear that as time went on and with the technological advances, complications decreased. However, efforts to improve neurological, vascular and mechanical complications and especially poor positioning, should not be abandoned.

These results should be carefully evaluated, since there are several potential sources of heterogeneity, besides the different population that has been considered in the studies. Pedicular screw insertions are complex interventions and it is difficult to avoid trends in comparison groups, since there are multiple diseases that affect different ages, ethnicities and genres [11].

\section{Conclusion}

The different ways of screw positioning may also be related to the surgeon's skills as well as the length and diameter of the pedicle screw that was introduced. We should try to deviate from this line of thought, including only meta-analyzes, prospective in vivo studies, and randomized studies, as they provide stronger evidence for meta-analysis.

Certainly, the complications caused by poor positioning of the pedicle screws are the most common. It is concluded that there is a growing need for a true improvement of methods that allow a safer intraoperative positioning of the screws.

6 Kosmopoulos V, Schizas C (2007) Pedicle screw placement accuracy: A meta-analysis. Spine (Phila Pa 1976) 32: 111-120.

7 Li G, Lv G, Passias P, Kozanek M, Metkar US, et al. (2010) Complications associated with thoracic pedicle screws in spinal deformity. Eur Spine 19: 1576-1584.

8 Roy-Camille R, Saillant G, Mazel C (1986) Internal fixation of the lumbar spine with pedicle screw plating. Clin Orthop Relat Res 203: 7-17.

9 Suk SE-II, Kim WJ, Lee SM, Kim JH, Chung ER (2001) Thoracic pedicle screw fixation in spinal deformities: Are they really safe? Eur Spine J 26: 2049-2057.

10 Verma R, Krishan S, Haendlmayer K, Mohsen A (2010) Functional outcome of computer-assisted spinal pedicle screw placement: A systematic review and meta-analysis of 23 studies including 5,992 pedicle screws. Eur Spine J 19: 370-375.

11 Wegener B, Birkenmaier C, Fottner A, Jansson V, Dürr HR (2008) Delayed perforation of the aorta by a thoracic pedicle screw. Eur Spine J 17: 351-354. 